\title{
UPLC/ESI-MS Phytochemical Screening of Deverra tortuosa Haematological and Histopathological Studies and Streptozotocin-Induced Diabetes in Rat
}

\author{
Fahad A. Alhumaydhi ${ }^{(D)},{ }^{1}$ Abdullah S. M. Aljohani ${ }^{D}{ }^{2},{ }^{2}$ and Eman R. Elsharkawy $\mathbb{D}^{3,4}$ \\ ${ }^{1}$ Department of Medical Laboratories, College of Applied Medical Sciences, Qassim University, Buraydah, Saudi Arabia \\ ${ }^{2}$ Department of Veterinary Medicine, College of Agriculture and Veterinary Medicine, Qassim University, \\ Buraydah, Saudi Arabia \\ ${ }^{3}$ Department of Eco Physiology, Ecology and Range Management Division, Desert Research Center, \\ Mathef El-Mataria 15753, Egypt \\ ${ }^{4}$ Department of Chemistry, Faculty of Science, Northern Border University, Arar, Saudi Arabia
}

Correspondence should be addressed to Eman R. Elsharkawy; elsharqawyeman2017@gmail.com

Received 3 August 2021; Revised 18 September 2021; Accepted 8 October 2021; Published 28 October 2021

Academic Editor: Riaz Ullah

Copyright ( 2021 Fahad A. Alhumaydhi et al. This is an open access article distributed under the Creative Commons Attribution License, which permits unrestricted use, distribution, and reproduction in any medium, provided the original work is properly cited.

\begin{abstract}
Herbal plants represent a new source of hypoglycemic antidiabetic drugs; haematological and histopathological studies of methanol extract of Deverra tortuosa in streptozotocin-induced diabetic rats were investigated in vivo. A single intraperitoneal injection of $160 \mathrm{mg} / \mathrm{kg}$ bodyweights of streptozotocin was used to cause diabetes. Blood glucose levels were tested with an AccuCheck Advantage II glucometer and blood glucose test strips. After diabetes was confirmed, animals were orally treated with the extract, metformin, and insulin according to the experimental design. After extract therapy, histological alterations in the pancreas of diabetic rats were investigated. When compared to a control group, daily oral administration of $D$. tortuosa extract $(300 \mathrm{mg} / \mathrm{kg}$ body weight) plus metformin $(100 \mathrm{mg} / \mathrm{kg}$ ) had a positive effect on blood glucose levels as well as showed an increased number of white blood cells (WBCs) and red blood cells (RBCs). The treatment with the extract for two weeks showed a positive impact on pancreatic histopathological changes in the groups with the diabetic rats. Phenolic fraction of the methanol extract was screened by the liquid chromatography-mass spectroscopy (LC-MS) method, which unveiled the existence of flavonoid compounds and phenolics as kaempferol, rutin, isorhamnetin-3-O-rutinoside, caffeic acid, and 4hydroxybenzoic acid 4-O-glucoside. The results confirmed the use of the plant as an antidiabetic agent; the research recommended further studies on the plant to use the plant as an antidiabetic drug, where the plant extract also showed improvement in blood parameters.
\end{abstract}

\section{Introduction}

The use of herbal medicines has increased in the last decade because of their effectiveness, safety, and affordability. WHO recommended the use of traditional plants in the treatment of diabetes. Products isolated from medicinal plants are usually used in the traditional Indian system and have shown clinical antidiabetic activity [1]. One of the dangerous diseases that developed due to irregularities in the metabolism of carbohydrate, protein, and fat is diabetes mellitus which influences insulin hormone. All of this is linked to oxidative stress, which is caused by a rise in free radical levels and a drop in antioxidant defenses [2].

$D$. tortuosa is used as "edible food; its aerial parts are used as fuel wood and have many medical uses. Saudi Arabian plant $D$. tortuosa showed antioxidant, allelopathic, and antifungal activity, used in traditional medicine as a drug for hypertension and against conception $[3,4]$. Azzazi et al. described the major compound of essential oil was terpinen-4-ol [5]. D. tortuosa is a salt-tolerant plant; it is 
grown in many phytogeographical habitats in Egypt, in desert wadis, sandy, and stony plains. This plant is dispersed in Egypt, Tunisia, Libya, and Saudi Arabia [6].

D. tortuosa (Arabic name is Shabat Elgabal) belongs to Apiaceae family, is an Arabic name, and has an aromatic scent; it is characterized by a high concentration of phytochemical compounds, flavonoids, coumarins, furanocoumarin, glucosides, and terpenes $[7,8]$. The plant was pharmacologically active and is used to treat asthma, hepatitis, fever, and diabetes. Ethyl acetate extract of $D$. tortuosa has anti-Candida activity and antivirulence activity [9].

The current research was aimed to evaluate the role of plant $D$. tortuosa as an antidiabetic through studying the effect of plant extract in vivo on albino diabetic rats; histopathology was studied to clarify the role of plant extract on pancreatic tissues; haematological studies were used to show the effect of treatment by herb on blood parameters.

\section{Materials and Methods}

2.1. Plant Material. The fresh plant sample (Figure 1) was collected in the spring season in the year 2018 from the northern region, Saudi Arabia. The sample was defined in the Biology Department, Faculty of Science, and the authentic sample (FSNBU.C.D.25) was deposited in the Chemistry Department.

2.2. Plant Extraction. Plant sample was dried at room temperature, the aerial part was grounded for fine powder, methanol extract was prepared by maceration method, and the plant powder $(500 \mathrm{~g})$ was soaked in methanol for 24 hours in a shaker at $25^{\circ} \mathrm{C}$. Then, the extract was filtered and stored at $-4^{\circ} \mathrm{C}$ for further investigation [10].

2.3. Experimental Animal. 150-180 gm weighted adult healthy albino Male rats were used for the experimental study. The animals were housed at regular conditions (temperature, $25 \pm 2^{\circ} \mathrm{C}, 55 \pm 5 \%$ relative humidity, and 12 hour light-dark cycle). Water and a normal diet were allowed to all animals $(21 \%$ crude protein, $7 \%$ crude fiber, $3 \%$ fat, $13 \%$ moisture, $8 \%$ ash, mineral, $1 \%$ calcium, $0.5 \%$ phosphorus, and $46.3 \%$ protein). All experimental procedures were in accordance with the guidelines and instructions of Scientific Research Ethics (COSRE) in Laboratory of Molecular Genetics (Egyptian Association for Sustainable Agri.), Egypt (Ethical Approval number: AM/115/01/21).

2.4. Experimental Design. Induction of diabetes was done by single intraperitoneal (i.p.) injection of STZ in a dose of $58 \mathrm{mg} / \mathrm{kg}$. Thirty animals were used and divided in to 5 groups (six animals per each):

Group 1: control group, only saline injection.

Group 2: diabetic group injected with $58 \mathrm{mg} / \mathrm{kg}$ STZ i.p.

Group 3: diabetic group injected with metformin with $100 \mathrm{mg} / \mathrm{kg}$ body weight for 2 weeks.

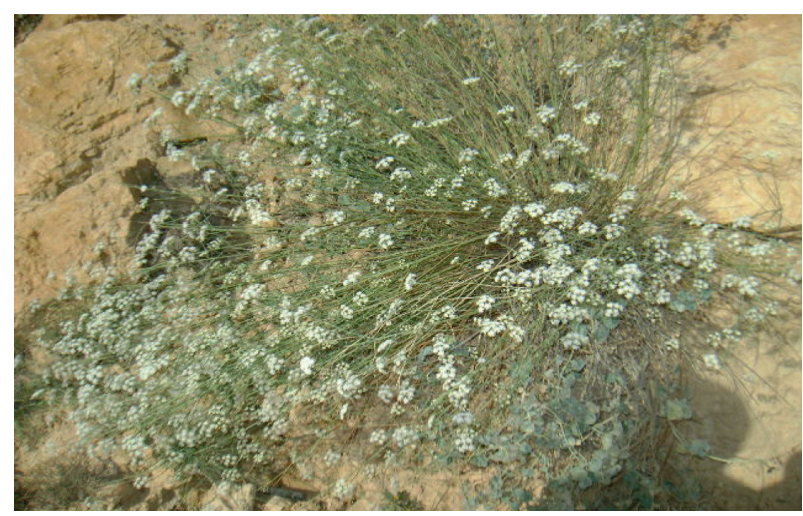

Figure 1: Picture of plant Deverra tortuosa.

Group 4: diabetic group injected with insulin at a dose of $10 \mathrm{U} / \mathrm{kg}$ body weight for 2 weeks.

Group 5: diabetic group injected with plant extract at a dose of $300 \mathrm{mg} / \mathrm{kg}$ body weight for 2 weeks.

2.5. Toxicity Studies. The OECD guideline no. 420 was used to conduct an acute toxicity test on a plant extract (Organization of Economic Co-operation and Development) according to the methods described by Elsharkawy et al. [11] At the conclusion of the trial, no fatalities were recorded, and the plant extract was confirmed to be safe up to a dosage of $2,000 \mathrm{mg} / \mathrm{kg}$.

2.6. Haematological Study. Blood samples were taken from each rat after the treatment and recovery period. The analysis was done for estimation of hemoglobin concentration according to Drabkin and Austin [12], red blood cells (RBCs) were counted according to Dacie and Lewis [13], and white blood cells (WBCs) were counted according to Mitruka et al. [14].

2.7. Histopathological Analysis of the Pancreatic Tissue. The pancreatic tissue samples were fixed in $10 \%$ formalin solution for 48 hours before being rinsed under running water for 8 hours for histopathological examination. During the usual tissue control phase, they were treated with alcohol $\left(70^{\circ}, 80^{\circ}, 90^{\circ}, 96^{\circ}\right.$, and $\left.100^{\circ}\right)$ and a succession of xylenes before being blocked in paraffin. On the slides, the samples were produced by cutting $4 \mu \mathrm{m}$ pieces from each block. They were stained with hematoxylin-eosin (HE) staining and prepared for histopathological examination. A light microscope was used to image and examine the relevant regions (Olympus BX51 optical microscope and Olympus DP25 digital camera, Japan) [15].

2.8. UPLC/MS Analysis. The sample $(100 \mu \mathrm{g} / \mathrm{mL})$ solution was prepared using high-performance liquid chromatography (HPLC) analytical grade solvent of $\mathrm{MeOH}$, filtered using a membrane disc filter $(0.2 \mu \mathrm{m})$, and then subjected to LC-ESI-MS analysis. Sample injection volumes $(10 \mu \mathrm{L})$ were injected into the UPLC instrument equipped with a reverse 
phase C-18 column (ACQUITY UPLC-BEH C-18, $1.7 \mu \mathrm{m}$ particle size $-2.1 \times 50 \mathrm{~mm}$ column). The sample mobile phase was prepared by filtering using a $0.2 \mu \mathrm{m}$ membrane disc filter and degassed by sonication before injection.

A gradient mobile phase included two eluents: eluent $\mathrm{A}$ is $\mathrm{H}_{2} \mathrm{O}$ acidified with 0.1 percent formic acid, and eluent $\mathrm{B}$ is $\mathrm{MeOH}$ acidified with 0.1 percent formic acid. Mobile phase elution was performed at a flow rate of $0.2 \mathrm{~mL} / \mathrm{min}$ with a flow rate of $0.2 \mathrm{~mL} / \mathrm{min}$. The aforementioned gradient was used for elution. The following parameters were used for the analysis: source temperature of $150^{\circ} \mathrm{C}$, cone voltage of $30 \mathrm{eV}$, capillary voltage of $3 \mathrm{kV}$, desolvation temperature of $440^{\circ} \mathrm{C}$, cone gas flow of $50 \mathrm{~L} / \mathrm{h}$, and desolvation gas flow of $900 \mathrm{~L} / \mathrm{h}$ in negative ion mode. Between m/z 100 and 1000, mass spectra were identified using the ESI negative ion mode. The peaks and the spectra were analyzed using the MassLynx 4.1 software and tentatively recognized by correlating the retention time (Rt) and mass spectrum to the data.

2.9. Statistical Analysis. Quantitative data were expressed as the mean \pm standard error of means. A paired-sample $t$-test was employed to determine if there were any significant differences between each tested compound with the referenced antifungal drug. The program used was Statistical Package for the Social Sciences (SPSS), version 11.

\section{Results and Discussion}

3.1. Toxicity Studies. Oral administration of alcoholic extract of $D$. tortuosa in doses up to $2,000 \mathrm{mg} / \mathrm{kg}$ failed to kill albino Male rats within $24 \mathrm{~h}$. The tested extract is considered highly safe, since substances possessing LD50 higher than $50 \mathrm{mg} / \mathrm{kg}$ b.wt. are considered nontoxic [11].

\subsection{Effect of Herbal Extracts on Blood Glucose Level.} Table 1 and Figure 2 show the findings of a two-week investigation on the effects of metformin, insulin, and plant extract on blood glucose levels in normal and diabetic rats subjected to various treatments. Control group showed normal blood glucose level with an average value of $90.6 \mathrm{mg} /$ dl. The diabetic group recorded a significant increase in blood glucose level $(541.6 \mathrm{mg} / \mathrm{dl})$, compared with normal controls; similarly, metformin and insulin diabetic-treated groups recorded a substantial fall in the levels of blood glucose (194.8 and $133.8 \mathrm{mg} / \mathrm{dl}$, respectively), compared with the diabetic group. The treatment with plant extract recorded a significant decrease in blood glucose level $(284 \mathrm{mg} / \mathrm{dl})$, compared with the diabetic group. Taken into consideration, the treated groups except the insulin group showed significant elevation in blood glucose level.

\subsection{Effects of Herbal Extracts on Insulin Levels in the Blood.} The impacts of metformin, insulin, and herbal extracts on blood insulin levels in normal and diabetic rats subjected to various treatments for 2 weeks are reported in Table 2 and Figure 3. The control group showed a normal blood insulin level with an average value of $1.38(\mathrm{ng} / \mathrm{ml})$.
TABLE 1: Effect of metformin, insulin, and plant extract on blood glucose level.

\begin{tabular}{lc}
\hline Groups & Blood glucose level $(\mathrm{mg} / \mathrm{dl})$ \\
\hline Control G1 & $90.6 \pm 5.9$ \\
STZ G2 & $541.5 \pm 15.39^{\mathrm{a}}$ \\
STZ + met (G3) & $194.8 \pm 12.8^{\mathrm{a}, \mathrm{b}}$ \\
STZ + insulin (G4) & $133.8 \pm 12.46^{\mathrm{b}}$ \\
STZ + herb (G5) & $284 \pm 19.9^{\mathrm{a}, \mathrm{b}}$ \\
\hline
\end{tabular}

Data are presented as means \pm SEM $(n=6)$. ${ }^{\text {a Significantly different from }}$

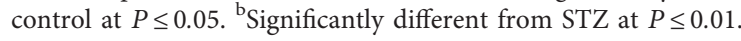

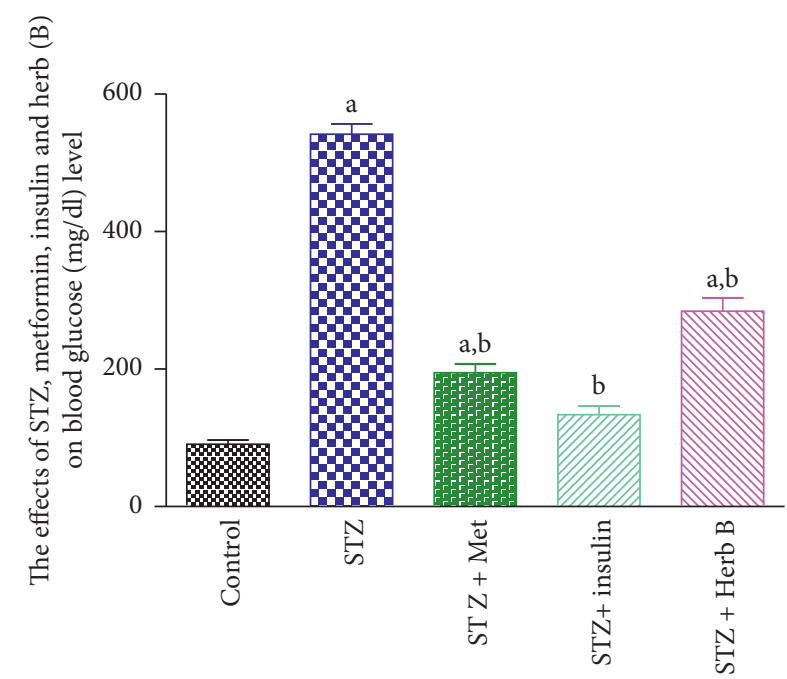

Figure 2: Effects of metformin, insulin, and herbal extract on the blood glucose level in normal and diabetic rats. ${ }^{a}$ Significantly different from control at $P \leq 0.05$. ${ }^{b}$ Significantly different from STZ at $P \leq 0.05$.

Meanwhile, diabetic groups recorded a substantial fall $(P<0.05)$ in the level of blood insulin $(0.33 \mathrm{ng} / \mathrm{ml})$, when compared with the normal control. Similarly, the metformin-treated group showed no noteworthy growth, while insulin diabetic-treated groups recorded a considerable boost $(P<0.05)$ in blood insulin levels $(0.89$ and $1.29 \mathrm{ng} / \mathrm{ml}$, respectively) when compared to the normal group. The treatment with herbal extract showed a mild decrease in blood insulin level $(0.93 \mathrm{ng} / \mathrm{ml})$ when compared with the normal group.

\subsection{Effects of Herbal Extracts on Body Weight in Diabetic and} Normal Rats. The effects of metformin, insulin, and herbal extracts on body weight in normal and diabetic rats subjected to various treatments for two weeks are summarized in Table 3 and illustrated in Figure 4. Control group showed normal body weight gain with normal increase (12\%) during the two weeks of study experiments. Meanwhile diabetic groups recorded a significant decrease $(P<0.05)$ in body weight $(17 \%)$ when compared with the initial weight. Similarly, the metformin and insulin diabetic-treated groups recorded a significant decrease $(P<0.05)$ in body weight ( $2.9 \%$ and $3.4 \%$, respectively) when compared with the initial weight. The treatment with herbal extracts recorded a 
TABLE 2: Effects of metformin, insulin, and herbal extract on the blood insulin level in normal and diabetic rats.

\begin{tabular}{lc}
\hline Groups & Blood insulin level $(\mathrm{mg} / \mathrm{dl})$ \\
\hline Control & $1.38 \pm 0.17$ \\
STZ & $0.33 \pm 0.06^{\mathrm{a}}$ \\
STZ + met & $0.89 \pm 0.14$ \\
STZ + insulin & $1.29 \pm 0.17^{\mathrm{b}}$ \\
STZ + herb & $0.93 \pm 0.11$ \\
\hline
\end{tabular}

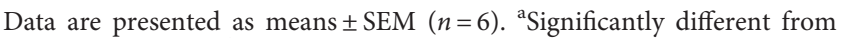

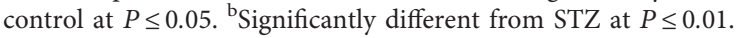

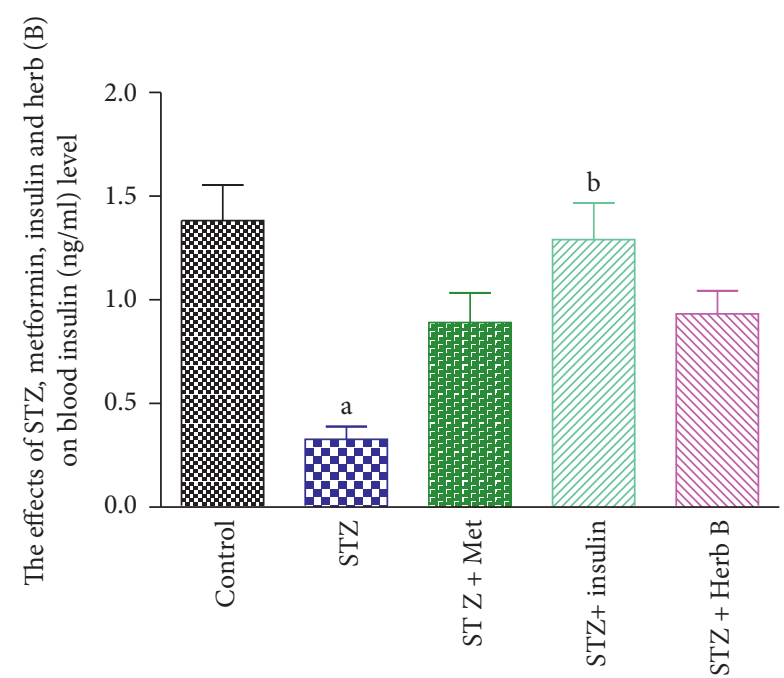

FIGURE 3: Effects of metformin, insulin, and herbal extract on the blood insulin level in normal and diabetic rats. ${ }^{\text {a Significantly }}$ different from control at $P \leq 0.05$. ${ }^{\text {b }}$ Significantly different from STZ at $P \leq 0.05$.

TABLE 3: Effects of metformin, insulin, and herbal extract on the percentage change in body weight in normal and diabetic rats.

\begin{tabular}{lc}
\hline Groups & Percentage change in body weight \\
\hline Control & $11.83 \pm 1.6$ \\
STZ & $-16.83 \pm 2.15$ \\
STZ + met & $-3.00 \pm 4.29$ \\
STZ + insulin & $-3.66 \pm 1.20$ \\
STZ + herb & $-7.00 \pm 2.59$ \\
\hline
\end{tabular}

Data are presented as means \pm SEM $(n=6)$. ${ }^{\text {a Significantly different from }}$ control at $P \leq 0.05$. ' Significantly different from STZ at $P \leq 0.01$.

significant decrease $(P<0.05)$ in body weight $(7.5 \%)$ when compared with the initial weight.

\subsection{Effects of Herbal Extracts on Hemoglobin Concentration,} Red Blood Cell Count, and Platelet Count. The control group showed normal RBC count, $\mathrm{Hb}$ concentration, and platelet count. The diabetic group recorded a significant decrease $(P<0.05)$ in the RBC count $(46.8 \%)$, Hb concentration $(10.8 \%)$, and platelet count $(37.4 \%)$ when compared with the corresponding control values.

Similarly, the metformin and insulin diabetic-treated groups recorded a noteworthy upsurge $(P<0.05)$ in the RBC

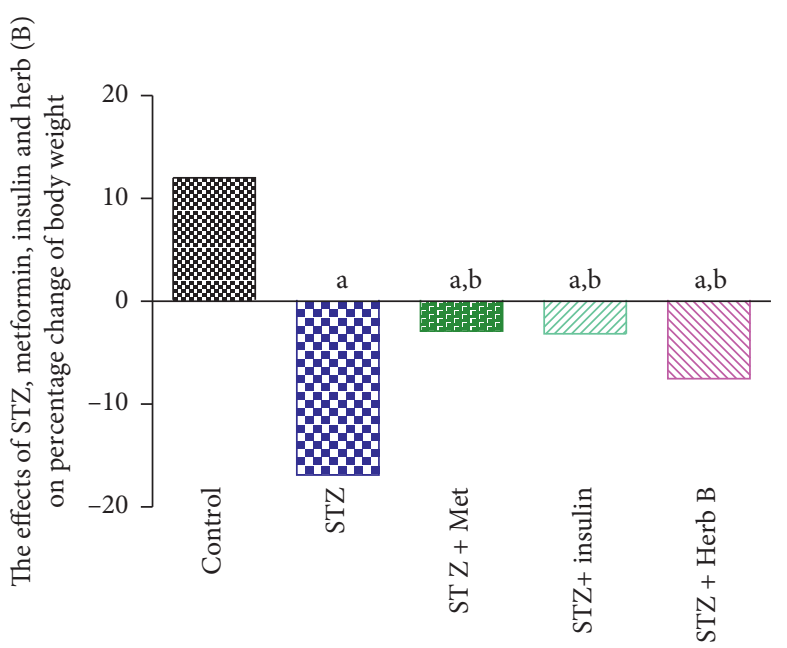

FIGURE 4: Effects of metformin, insulin, and herbal extract on percentage change in the body weight in normal and diabetic rats. ${ }^{\mathrm{a}}$ Significantly different from control at $P \leq 0.05$. ${ }^{\mathrm{b}}$ Significantly different from STZ at $P \leq 0.05$.

count ( $98.4 \%$ and $84.03 \%$, respectively), the $\mathrm{Hb}$ concentration in metformin and insulin diabetic-treated groups recorded no significant change $(1.4 \%$ and $-2.8 \%$, respectively), and platelet count in metformin diabetic-treated group recorded no significant increase $(36.7 \%)$, while the insulin diabetic-treated groups recorded significant increase (54.7\%) when compared with the corresponding values in the diabetic group. The treatment with herbal extract exhibited a substantial increase $(P<0.05)$ in the count of RBCs (80.7\%); finally, the platelet count showed a significant decrease in the herb by about $76.4 \%$, when compared with the corresponding values in the diabetic-treated group as shown in Table 4 and Figures 5-7.

3.6. Effects of Herbal Extracts on the White Blood Cell (WBC) Count in Normal and Diabetic Rats Exposed to Different Treatments. The effect of methanol extract of $D$. tortuosa on WBC count is illustrated in Table 5 and Figure 8 . The diabetic group recorded a considerable decline $(P<0.05)$ in WBC quantities (46.01\%) when compared with the corresponding control values. Similarly, the metformin and insulin diabetic-treated groups recorded a substantial increase $(P<0.05)$ in the count of WBCs $(118.03 \%$ and $95.1 \%$, respectively) when compared with the corresponding diabetic groups. The treatment with plant extract recorded a substantial increase $(P<0.05)$ in WBCs $(78.7 \%)$ when compared with the corresponding diabetic groups.

3.7. Histopathological Study of the Pancreas. Figure 9 shows the histopathological structure of pancreatic tissue. The pancreatic B cell of Group 2 diabetic rats was completely damaged compared to control Group 1 due to STZ induction, and it was discovered that, after treatment with methanol extract of $D$. tortuosa, the atrophy of Langerhans islets, degeneration, and apoptosis by B cell decreased, and pancreatic structure was restored in diabetic rats. 


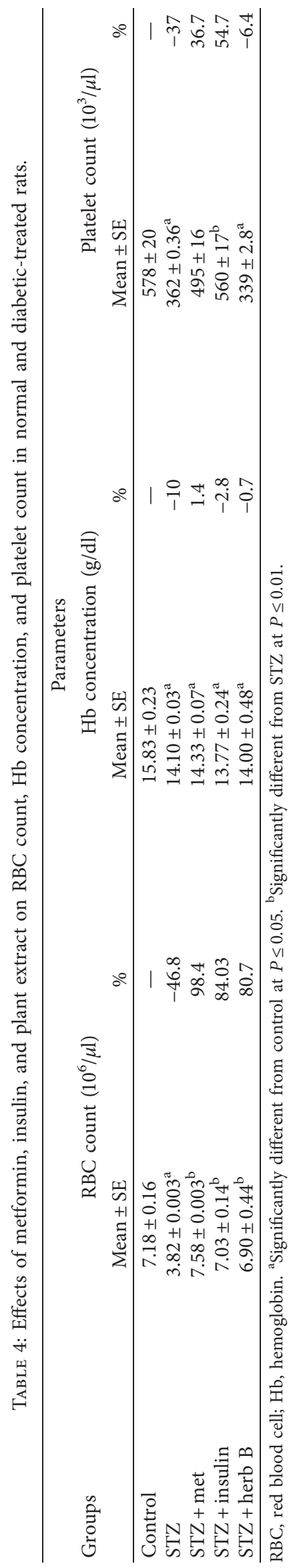




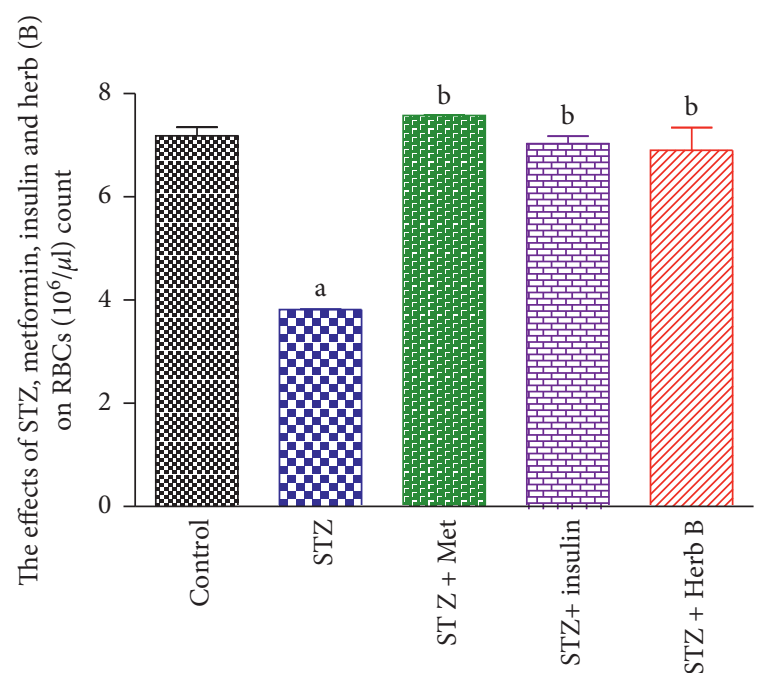

Figure 5: Effects of metformin, insulin, and herbal extract on the

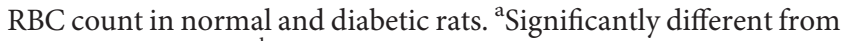
control at $P \leq 0.05$. ' Significantly different from STZ at $P \leq 0.05$.

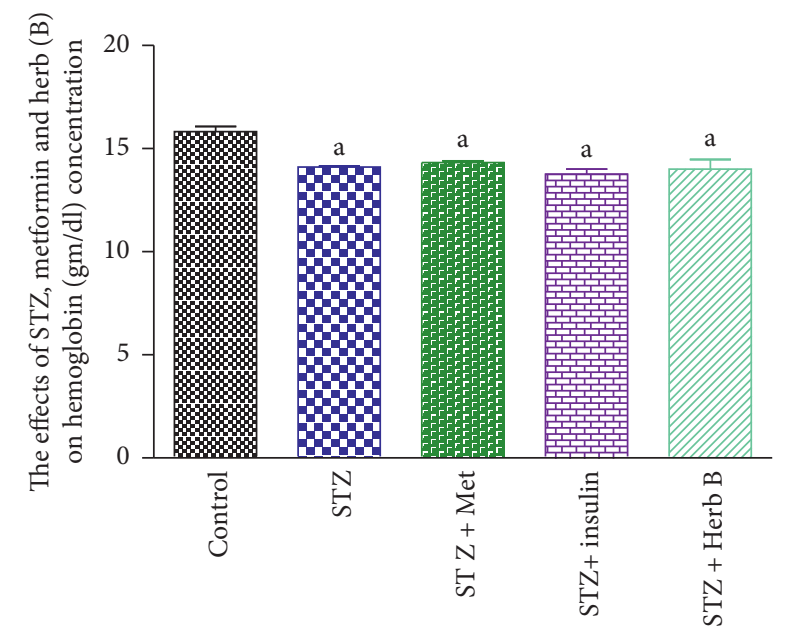

FIGURE 6: Effects of metformin, insulin, and herbal extract on the $\mathrm{Hb}$ concentration in normal and diabetic rats. Data are presented as

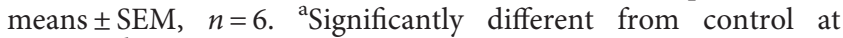
$P \leq 0.05$. ${ }^{\text {b }}$ Significantly different from STZ at $P \leq 0.05$.

Additionally, metformin treatment changed the pancreatic structure.

3.8. UPLC-QTOF/ESI-MS Screening. Ultraperformance liquid chromatography in combination with mass spectrometry method was deployed to examine the phytochemical components in plant extract, the phenolic fraction of methanol extract was analyzed by UPLC/ESI-MS, phytochemical screening of plant extract revealed the presence of a high amount of flavonoid compounds, and this was confirmed by identification of flavonoid, flavonoid glucoside, and phenolic acid by using positive mode (+) ESI-Ms, and the identification of compounds was determined on the basis of the pattern of mass fragments and ion response. Compounds were identified as listed in Table 6, and

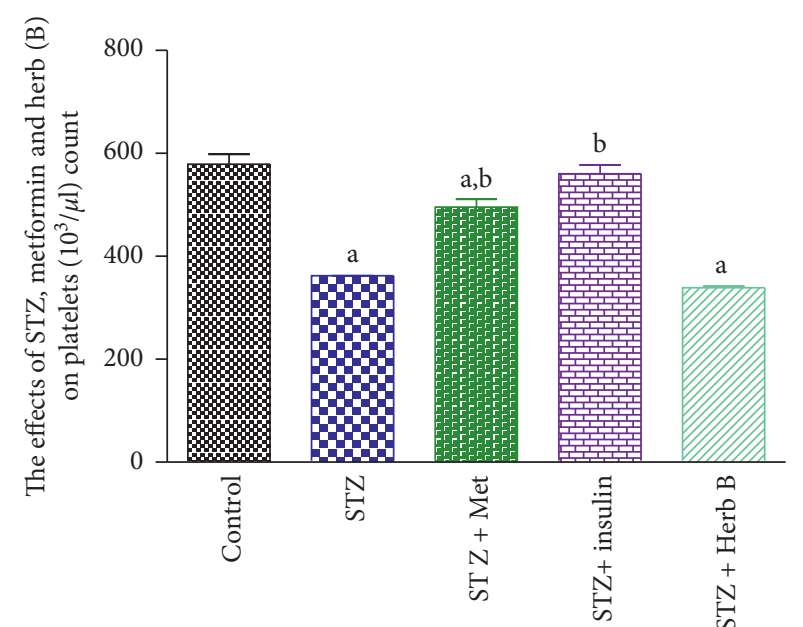

Figure 7: Effects of metformin, insulin, and herbal extract on the platelet count in normal and diabetic rats. Data are presented as

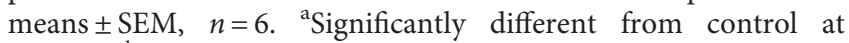
$P \leq 0.05$. ${ }^{\mathrm{b}}$ Significantly different from $\mathrm{STZ}$ at $P \leq 0.05$.

TABLE 5: Effects of metformin, insulin, and herbal extract on WBC count in normal and diabetic rats exposed to different treatments.

\begin{tabular}{lc}
\hline Groups & WBCs $\left(10^{3} / \mu \mathrm{l}\right)$ \\
\hline Control & $11.33 \pm 0.14$ \\
STZ & $6.10 \pm 0.036^{\mathrm{a}}$ \\
STZ + met & $13.33 \pm 2.13^{\mathrm{b}}$ \\
STZ + insulin & $11.90 \pm 1.18^{\mathrm{b}}$ \\
STZ + herb & $10.90 \pm 0.56^{\mathrm{b}}$ \\
\hline
\end{tabular}

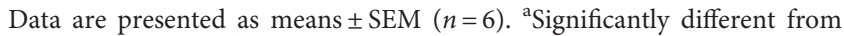
control at $P \leq 0.05$. ${ }^{\text {b }}$ Significantly different from STZ at $P \leq 0.01$.

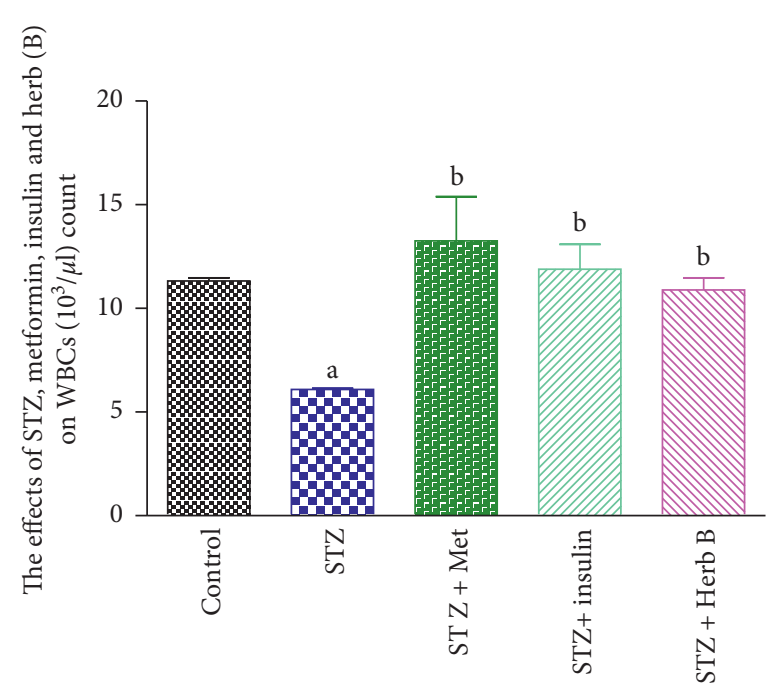

FIgURE 8: Effects of metformin, insulin, and herbal extract on the

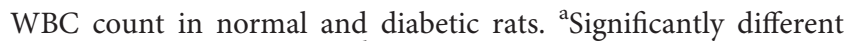
from control at $P \leq 0.05$. ' Significantly different from STZ at $P \leq 0.05$.

chromatograms are presented in Figure 10. Molecular formula and molecular weight were compared with $[16,17]$. 


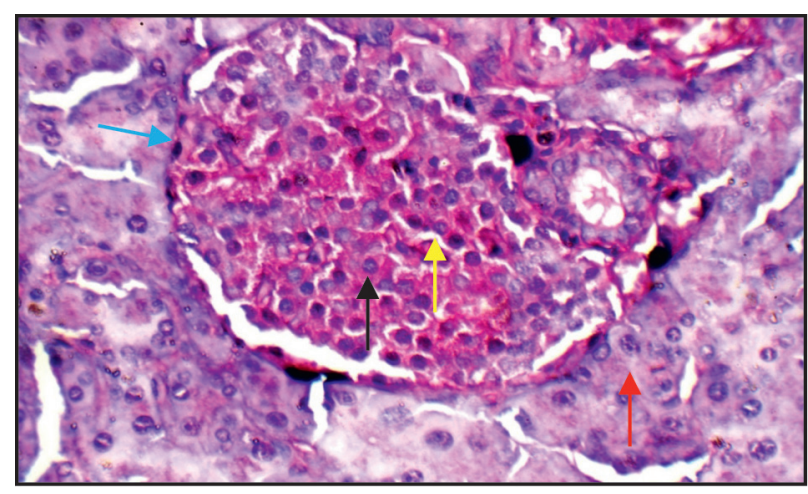

(a)

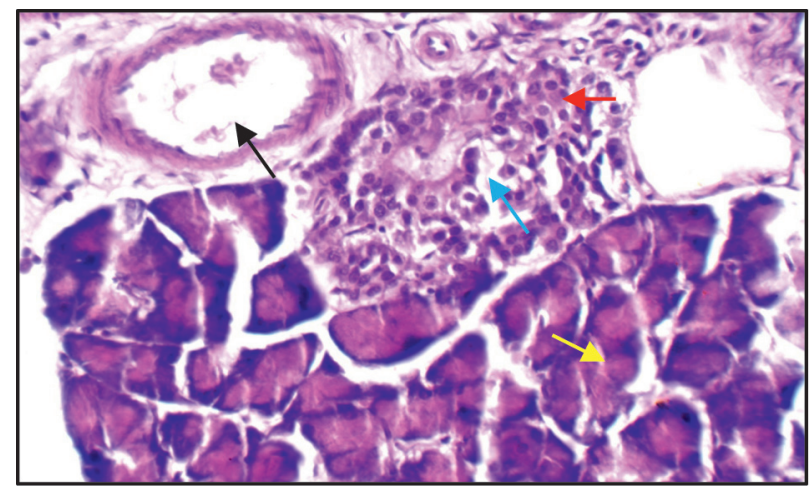

(c)

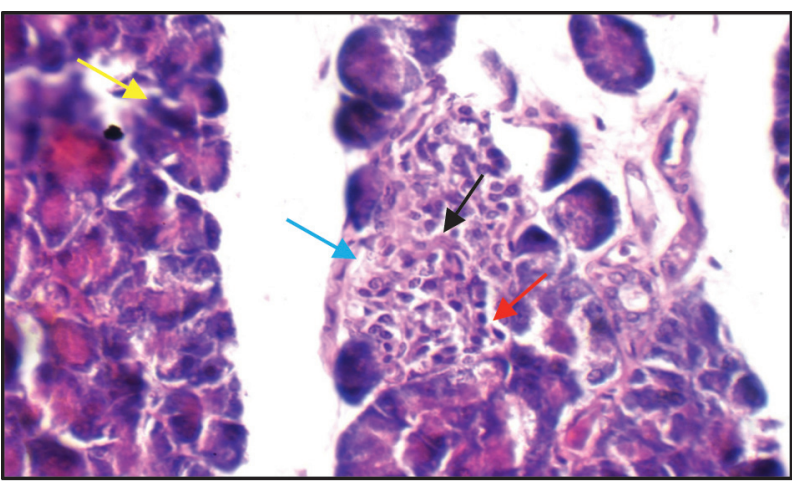

(b)

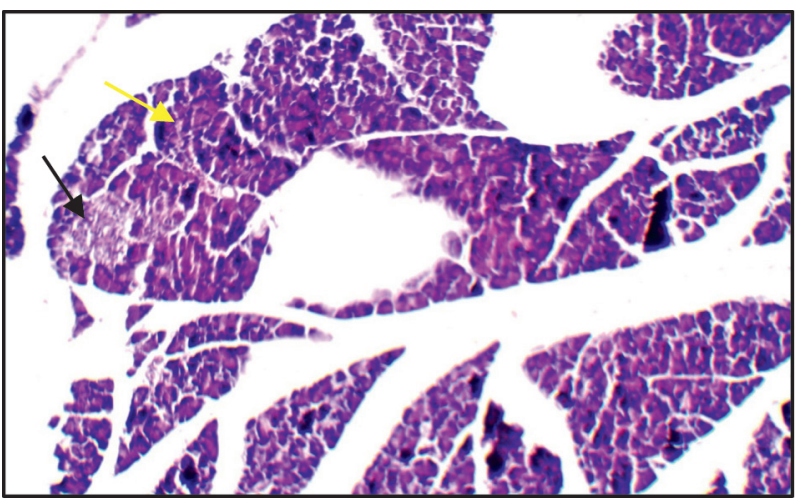

(d)

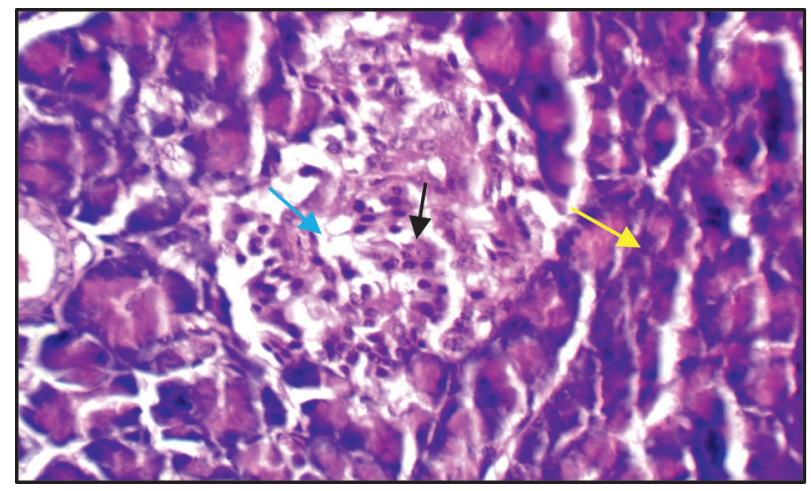

(e)

FIGURE 9: Histopathological structure of the normal pancreas. (a) The normal pancreas showing average-sized normocellular islets with predominating beta cells (black arrow) and less frequently alpha cells in the periphery (blue arrow), average intervening blood capillaries (yellow arrow), and average exocrine areas (red arrow) (H\&E $\times 400)$. (b) The diabetic pancreas showing relatively small-sized islets with apoptotic beta cells (black arrow), excess alpha cells (red arrow), average intervening blood capillaries (blue arrow), and average exocrine areas (yellow arrow) $(\mathrm{H} \& \mathrm{E} \times 400)$. (c) The metformin-treated pancreas showing average islet with average beta cells (red arrow), mildly dilated intervening blood capillaries (blue arrow), average exocrine areas (yellow arrow), and mildly congested blood vessels (black arrow) $(\mathrm{H} \& \mathrm{E} \times 400)$. (d) The insulin-treated group showing relatively small-sized pale-staining islets of Langerhans (black arrow) and average exocrine areas (yellow arrow) $(\mathrm{H} \& \mathrm{E} \times 200)$. (e) Herb treatment showing hypocellular islets with scattered beta cells (black arrow) with mildly dilated intervening blood capillaries (blue arrow) and average exocrine areas (yellow arrow) (H\&E $\times 400)$.

The chemical was identified using literature data to compare the molecular ion peak $(\mathrm{M}-\mathrm{H})$ and fragmentation patterns derived from MS/MS $[18,19]$. From the fragmentation pattern, the simple regular cleavage of glucoside bonds in the molecular ion peaks $[\mathrm{M}-\mathrm{H}]$ can be concluded, as an example in the spectra of flavonol-3-glucoside; the successive loss of a glycone gives fragment ion at 315, (314) $\mathrm{m} / \mathrm{z} 285$ (284), m/z, 151 (isorhamnetin), fragment ion peak 
Table 6: Compounds identified from the phenolic fraction of D. tortuosa by the HPLC-MS negative mode.

\begin{tabular}{|c|c|c|c|c|c|}
\hline No. & $\begin{array}{c}\mathrm{Rt} \\
(\mathrm{min})\end{array}$ & $\%$ & $\begin{array}{l}{[\mathrm{M}-} \\
\mathrm{H}]^{-}\end{array}$ & MS/MS & Identified compound (M) \\
\hline 1 & 5.62 & 3.2 & 299 & MS2 [137]: (100) [M-H-Glc], 93 [M-H-Glc-CO2] & $\begin{array}{l}\text { 4-Hydroxybenzoic acid 4-O- } \\
\text { glucoside }\end{array}$ \\
\hline 2 & 7.44 & 6.18 & 477 & MS2 [301]: (100), 151, 135 & Quercetin 3-O-glucuronide \\
\hline 3 & 9.28 & 2.20 & 341 & $303,257,193$ & Hesperidin derivative $(342)$ \\
\hline 4 & 9.63 & 1.04 & 447 & $\begin{array}{c}\text { MS2 [447]: } 429 \text { (2), } 415(2), 285 \text { (100); MS3 [285]: } 270(100), 257 \text { (4), } 253 \\
(40), 229(5), 225(16), 137(5)\end{array}$ & Kaempferol glucoside \\
\hline 5 & 15.65 & 5.6 & 447 & MS2 [300.9]: 178.8, 150.8, 106.9, 120.8, 272.9, 228.9, 256.8 & Quercetin 3-O- $\beta$-rhamnoside \\
\hline 6 & 20.25 & 7.5 & 593 & MS2: $285(100), 257(22)$ MS3 [593 $\longrightarrow 285]: 257$ & Kaempferol-3-O-rutinoside \\
\hline 7 & 23.76 & 8.08 & 301 & 257 (9100), 247, 201 & Quercetin \\
\hline 8 & 24.6 & 8.25 & 609 & 300 (100), 271, 255, 151 & Rutin \\
\hline 9 & 26.57 & 102.5 & 623 & $315(100), 300,271,255$ & Isorhamnetin-3-O-rutinoside \\
\hline 10 & 27.60 & 5.62 & 316 & MS2 [301] (100), 272, 256, 154, 107 & Isorhamnetin \\
\hline 11 & 28.03 & 1.78 & 179 & MS2: 161 (100), 135 & Caffeic acid \\
\hline 12 & 31.27 & 15.5 & 285 & $239,69(100), 187.22,143.21$ & Kaempferol \\
\hline
\end{tabular}

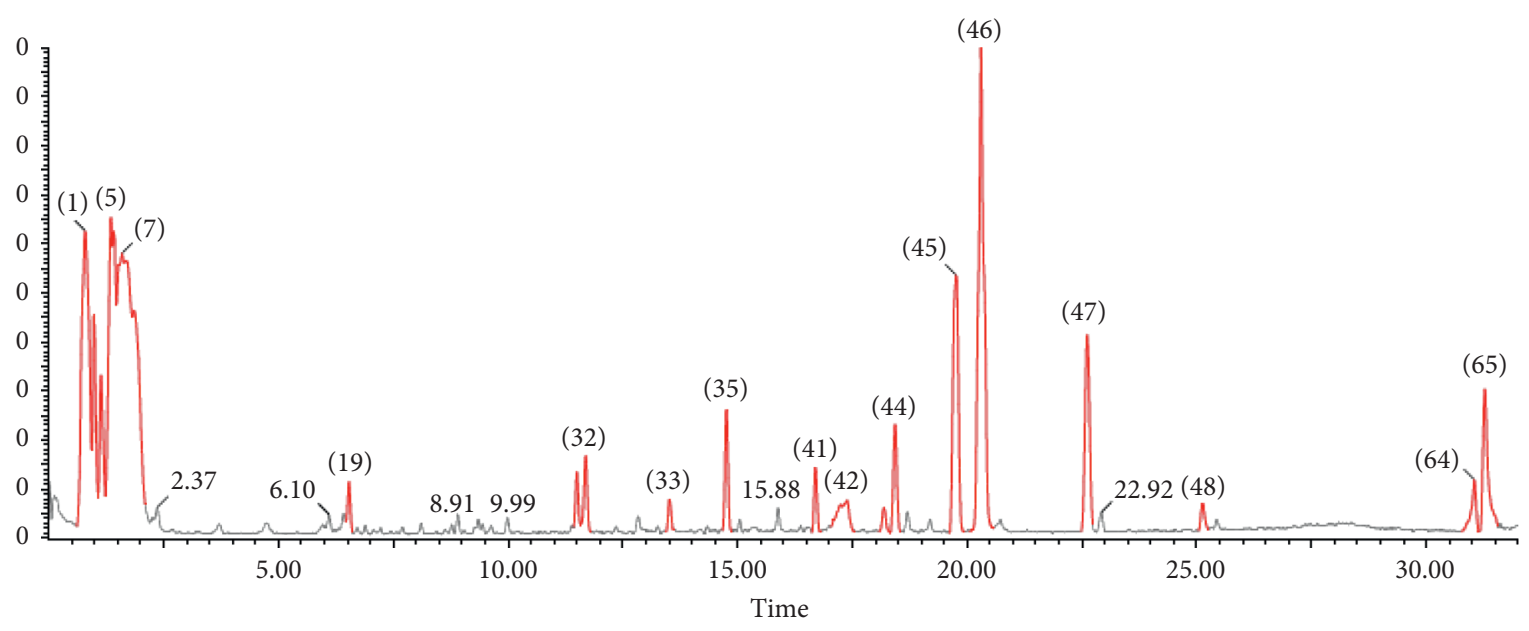

FIgURE 10: LC-MS chromatogram of the methanol extract of D. tortuosa.

at 315 due to loss of glucoside, and fragment ion at 301 [315$\mathrm{CH} 3$ ) due to loss of methyl group, while fragmentation of 301 through MS/MS gives three fragment peaks (257 [MCO2], 171, and 151) [20]. Kaempferol gives fragmentation pattern (284 [M-H], 255, 179, 151) despite homiletic cleavage of B ring [18].

\section{Discussion}

D. tortuosa is used as a traditional medicinal plant in Egypt and Saudi Arabia. The current study was assumed to examine the antidiabetic activity of methanol extract of the plant. Diabetes is a common disease spread in Arabian countries and the world affecting the major population. It is a metabolic disease, causing complication in many organs such as liver, kidney, and pancreas [21]. An experimental model was designed to examine how antidiabetic agents affect diabetes; STZ is used for experimental diabetes which has toxic effects on pancreatic beta cells and causes oxidant effects and the formation of nitric acid together with DNA damage. The results of this experimental study show that the plant extract exhibits significant antihyperglycemic activity at a dose level of $300 \mathrm{mg} \backslash \mathrm{kg}$. An increase of glucose level in blood induces the excretion of insulin which controls the production of glucose [22].

The diagnosis of diabetes on male Wister albino rats was confirmed by increased serum glucose level after 28 days of injection of STZ in diabetic rats. The serum glucose level was measured as $541.5 \pm 15.39 \mathrm{mg} / \mathrm{dL}$ in Group 2, as compared with the nondiabetic rats (control group). It was observed that the glucose levels of Groups 3 and 4 decrease, while the glucose levels of Group 5 were higher than those of Groups 3 and 4 but lower than those of Group 2 (STZ). The serum insulin level of Group 1 was $34.88 \pm 0.36 \mathrm{mg} / \mathrm{dl}$. The serum insulin level of the STZ induced rats (Group 2) was lower than that of Group $1(0.33 \pm 0.06 \mathrm{mg} / \mathrm{dl})$, while the herb (Group 5) showed a decrease in serum insulin level 
$(0.93 \pm 0.11 \mathrm{mg} / \mathrm{dl})$ more than Group 3 (metformin). This is common and agrees with a pervious study on Apiaceae family used to treat diabetes [23].

Flavonoid compounds have many biological activities; for example, they protect the body against oxidative stress. Flavonoid-rich food reduces the risk of oxidative compounds $[24,25]$. Isorhamnetin glycoside and kaempferol possess an antidiabetic effect and influence lipid content. Rutin showed a significantly lower level of plasma glucose and increased insulin level at $10 \mathrm{mg} / \mathrm{kg}$ in a previous study on diabetic mice [26]. There are many previous studies on antidiabetic activity of flavonoid compounds, which revealed the role of flavonoid compounds in the treatment of diabetes by different mechanisms. Most significant mechanisms are decreasing insulin resistance, inflammation, and oxidative stress in muscle by increasing insulin production, reducing apoptosis, and boosting profanation of pancreatic B cells [27]. The previous studies agreed with this study where the major compounds of a phenolic fraction rutin, kaempferol, and isorhamnetin-3-Orutinoside which have the potential antidiabetic effect, reflecting the role of the plant as an antidiabetic drug.

Study of the effect of a phenolic fraction on haematological parameters showed a decrease in $\mathrm{RBCs}, \mathrm{Hb}$ content, and platelet count in diabetic rats, and this decrease in $\mathrm{RBCs}$ and $\mathrm{Hb}$ indicated the rats suffer from anemia, as a result of the toxic effect of STZ. Meanwhile the treatment with herbal extract exhibited a significant increase in the RBC count $(80.7 \%)$. The platelet count showed a significant decrease in the herb-treated group, by approximately $76.4 \%$ when compared with the corresponding values in the diabetic-treated group, while there was no significant change in $\mathrm{Hb}$ concentration compared with the diabetic group. Current studies came to agree with other previous studies by Helal et al. [28] and were contradictory with Hadiya [29] who found that Nigella sativa extract caused significant increase in hemoglobin and platelet counts. The plant $D$. tortuosa in this study can be used as an antidiabetic drug and we recommended following the study on this plant.

\section{Conclusion}

In the current study, a glucose induction hyperglycemic model was selected to monitor the antihyperglycemic activity of plant extract. The results concluded that methanol extract of $D$. tortuosa decreases the blood glucose level and improves blood parameters, increasing WBCs and RBCs compared with the diabetic group. The extract also inhibits histopathological changes induced in the pancreas of diabetes group. Phytochemical screening by HPLC/MS of flavonoid fraction revealed the presence of more than 20 peaks; 12 peaks were identified by comparison with literature data. The major flavonoid compounds rutin, kaempferol and isorhamnetin-3-O-rutinoside confirmed the role of the plant as an antidiabetic because these compounds have antioxidant activity and decrease the oxidative stress, which is considered as one of the most important reasons for the pancreatic damage. These obtained results support the use of the plant in antidiabetic traditional preparations after further studies.

\section{Data Availability}

Data are available upon request to the corresponding author.

\section{Conflicts of Interest}

All authors declare that there are no conflicts of interest.

\section{Acknowledgments}

The researchers would like to thank the Deanship of Scientific Research, Qassim University, for funding the publication of this project.

\section{References}

[1] D. Patel, S. Prasad, R. Kumar, and S. Hemalatha, "An overview on antidiabetic medicinal plants having insulin mimetic property," Asian Pacific Journal of Tropical Biomedicine, vol. 2, no. 4, pp. 320-330, 2012.

[2] D. Gomathi, G. Ravikumar, M. Kalaiselvi, K. Devaki, and C. Uma, "Efficacy of evolvulus alsinoides (L.) L. on insulin and antioxidants activity in pancreas of streptozotocin induced diabetic rats," Journal of Diabetes and Metabolic Disorders, vol. 12, no. 1, pp. 39-46, 2013.

[3] R. D. de Castro, T. M. P. A. de Souza, L. M. D. Bezerra et al., "Antifungal activity and mode of action of thymol and its synergism with nystatin against Candida species involved with infections in the oral cavity: an in vitro study," $B M C$ Complementary and Alternative Medicine, vol. 15, no. 1, pp. 1-7, 2015.

[4] F. M. El-Mokasabi, "Floristic composition and traditional uses of plant species at Wadi Alkuf, Al-Jabal Al-Akhder, Libya," American-Eurasian Journal of Agricultural \& Environmental Sciences, vol. 14, no. 8, pp. 685-697, 2014.

[5] M. Azzazi, M. Afifi, O. Tammam, and A. Sheikh Alsouk, "Chemical composition and antifungal activity of the essential oil from deverratortuosa against phytopathogenic fungi," Swift Journals of Agricultural Research, vol. 1, pp. 28-32, 2015.

[6] L. Boulos, Flora of Egypt: With 409 Line Drawings and 94 Colour Photographs: Geraniaceae-Boraginaceae, Al Hadara Publishing, London, UK, 2000.

[7] A. Abdelwahed, N. Hayder, S. Kilani et al., "Chemical composition and antimicrobial activity of essential oils from tunisian pituranthos tortuosus (Coss.) maire," Flavour and Fragrance Journal, vol. 21, no. 1, pp. 129-133, 2006.

[8] H. M. Abdallah and S. M. Ezzat, "Effect of the method of preparation on the composition and cytotoxic activity of the essential oil of pituranthostortuosus," Zeitschrift für Naturforschung-Section C Journal of Biosciences, vol. 66, no. 3-4, pp. 143-148, 2011.

[9] M. Sharaf, "Evaluation of the antivirulence activity of ethyl acetate extract of deverra tortuosa (Desf) against Candida albicans," Egyptian Pharmaceutical Journal, vol. 19, no. 2, p. $188,2020$.

[10] N. N. Azwanida, "A review on the extraction methods use in medicinal plants, principle, strength and limitation," Medicinal \& Aromatic Plants, vol. 4, no. 196, pp. 412-2167, 2015.

[11] E. Elsharkawy, M. Alshathely, and G. A. Jaleel, "Role of catecholamine's compounds in anti-inflammatory and antioxidant of two plants santolina chamaecyparissus and launaea mucronata," Pakistan Journal of Nutrition, vol. 14, no. 10, pp. 672-679, 2015. 
[12] D. L. Drabkin and J. H. Austin, "Spectrophotometric studies," Journal of Biological Chemistry, vol. 112, no. 1, pp. 51-65, 1935.

[13] J. V. Dacie and S. M. Lewis, Evaluation of RB Cs in Hematology: The English Language Book Society and Churchill Living Stone, Edinburgh, New York, NY, USA, 1991.

[14] B. M. Mitruka and H. M. Rawnsley, "Clinical biochemical and hematological reference values in normal experimental animals," Journal of Clinical Pathology, vol. 32, no. 1, p. 96, 1977.

[15] A. Plazonić, F. Bucar, Z. Maleš, A. Mornar, B. Nigović, and N. Kujundzić, "Identification and quantification of flavonoids and phenolic acids in burr parsley (Caucalis platycarpos L.), using high-performance liquid chromatography with diode array detection and electrospray ionization mass spectrometry," Molecules, vol. 14, no. 7, pp. 2466-2490, 2009.

[16] Y. Chen, H. Yu, H. Wu et al., "Tracing novel hemostatic compounds from heating products of total flavonoids in flos sophorae by spectrum-effect relationships and column chromatography," Journal of Separation Science, vol. 38, no. 10, pp. 1691-1699, 2015.

[17] W. Tao, N. Yang, J.-A. Duan et al., "Simultaneous determination of eleven major flavonoids in the pollen of typha angustifolia by HPLC-PDA-MS," Phytochemical Analysis, vol. 22, no. 5, pp. 455-461, 2011.

[18] X. Wu, W. Ding, J. Zhong, J. Wan, and Z. Xie, "Simultaneous qualitative and quantitative determination of phenolic compounds in aloe barbadensis mill by liquid chromatography-mass spectrometry-ion trap-time-of-flight and high performance liquid chromatography-diode array detector," Journal of Pharmaceutical and Biomedical Analysis, vol. 80, pp. 94-106, 2013.

[19] L. Qimin, H. van den Heuvel, O. Delorenzo et al., "Mass spectral characterization of C-glycosidic flavonoids isolated from a medicinal plant (Passiflora incarnata)," Journal of Chromatography B: Biomedical Sciences and Applications, vol. 562, no. 1-2, pp. 435-446, 1991.

[20] G. Krishnasamy, K. Muthusamy, D. R. Chellappan, and N. Subbiah, "Antidiabetic, antihyperlipidaemic, and antioxidant activity of Syzygium densiflorum fruits in streptozotocin and nicotinamide-induced diabetic rats," Pharmaceutical Biology, vol. 54, no. 9, pp. 1716-1726, 2016.

[21] R. M. Pabbidi, D.-S. Cao, A. Parihar, M. E. Pauza, and L. S. Premkumar, "Direct role of streptozotocin in inducing thermal hyperalgesia by enhanced expression of transient receptor potential vanilloid 1 in sensory neurons," Molecular Pharmacology, vol. 73, no. 3, pp. 995-1004, 2008.

[22] A. G. Jagtap and P. B. Patil, "Antihyperglycemic activity and inhibition of advanced glycation end product formation by Cuminum cyminum in streptozotocin induced diabetic rats," Food and Chemical Toxicology, vol. 48, no. 8-9, pp. 2030-2036, 2010.

[23] N. K. Farkhad, F. Farokhi, and A. Tukmacki, "Hydro-alcoholic extract of the root of Prangosferulacea (L.) lindl can improve serum glucose and lipids in alloxan-induced diabetic rats," Avicenna journal of phytomedicine, vol. 2, no. 4, p. 179, 2012.

[24] T. Yokozawa, H. Y. Kim, E. J. Cho, J. S. Choi, and H. Y. Chung, "Antioxidant effects of isorhamnetin 3, 7-di-O$\beta$-d-glucopyranoside isolated from mustard leaf (Brassica juncea) in rats with streptozotocin-induced diabetes," Journal of Agricultural and Food Chemistry, vol. 50, no. 19, pp. 5490-5495, 2002.

[25] H. Alkhalidy, W. Moore, Y. Zhang et al., "Small molecule kaempferol promotes insulin sensitivity and preserved pancreatic $\beta$-cell mass in middle-aged obese diabetic mice,"
Journal of Diabetes Research, vol. 2015, Article ID 532984, 14 pages, 2015.

[26] P. S. M. Prince and N. Kamalakkannan, "Rutin improves glucose homeostasis in streptozotocin diabetic tissues by altering glycolytic and gluconeogenic enzymes," Journal of Biochemical and Molecular Toxicology, vol. 20, no. 2, pp. 96-102, 2006.

[27] R. Vinayagam and B. Xu, "Antidiabetic properties of dietary flavonoids: a cellular mechanism review," Nutrition \& Metabolism, vol. 12, no. 1, pp. 60-20, 2015.

[28] E. G. E. Helal, A. S. M. Gawish, and A. Kahwash, "Some hematological-studice ON diabetic RATS treated with certain hypoglycemic plants," The Egyptian Journal of Hospital Medicine, vol. 19, no. 1, pp. 179-188, 2005.

[29] S. A. Hadiya, "Effect of nigella seeds (black seed) extract on some hematological and biochemical parameters in rats," Alexandria Journal of Veterinary Sciences, vol. 11, pp. 95-99, 1995. 